\title{
FUZZY METHOD FOR ANALYSING UNCERTAINTY IN THE SUSTAINABLE DESIGN OF CONCRETE STRUCTURES
}

\author{
Alfredo del CAÑO, M. Pilar de la CRUZ, Diego GÓMEZ, Miguel PÉREZ \\ Universidade da Coruña, Escuela Politécnica Superior, C/ Mendizábal, S/N, 15.403 Ferrol, Spain
}

Received 06 Aug 2013; accepted 22 Apr 2014

\begin{abstract}
The model presented here is based on fuzzy arithmetic techniques and the MIVES method, which is based, in turn, on requirement trees, value analysis and the Analytic Hierarchy Process. Even though it encompasses the approach for assessing sustainability adopted by the Spanish Structural Concrete Code (EHE), the model can also be applied to concrete structures designed according to other structural codes. The EHE model serves to estimate the Structure's Contribution to Sustainability Index (ICES) and constitutes the first sustainability model included in a structural code. The ICES crisp model is inadequate in terms of managing the structural sustainability objective of medium and high uncertainty projects. In such cases, a method not only has to assess the potential sustainability index at the end of the project, but also the degree of uncertainty affecting compliance with the sustainability objective laid down by the client or promoter. The paper compares this model with a Monte Carlo simulation method conceived for the same purpose. The fuzzy method could be a better solution in specific cases of limited time or budget for creating the model.
\end{abstract}

Keywords: concrete structures, sustainable development, quantitative analysis, uncertainty, fuzzy arithmetic, decision support systems, MIVES, requirement trees, AHP, value analysis.

\section{Introduction}

There are many methods and publications regarding specific issues of sustainability, yet very few on integrating environmental, social and economic sustainability indicators. The MIVES method (Integrated Value Model for Sustainability Assessment, in translation from Spanish) (San-Jose, Cuadrado 2010; San-Jose, Garrucho 2010; Cuadrado et al. 2012; Gómez et al. 2012; Pons, Aguado 2012; Reyes et al. 2014) is a technique based on requirement trees (as per Fig. 1), value analysis (Alarcón et al. 2011) and the Analytic Hierarchy Process (AHP) (Saaty 1980, 2006). It serves to transform any group of quantitative and qualitative variables into a set of non-dimensional variables to facilitate their use in sustainability assessment and corresponding decision making. This is helpful when integrating the different environmental, social and economic factors to be incorporated into a sustainability assessment.

MIVES has been applied in the creation of the sustainability assessment model of the Spanish Code on Structural Concrete (Instrucción Española del Hormigón Estructural EHE-08, henceforth EHE; Ministerio de la Presidencia 2008; Aguado et al. 2012). This model is known as the Structure's Contribution to Sustainability Index (in translation, ICES, which is used in this paper) and constitutes the first sustainability model included in a structural code. Two of the present paper's authors formed part of the ICES development team.

Once the general sustainability objective and the ICES sub-objective for the structure are established, architects and engineers will design it. They will take into account the complete set of project objectives, including scope, cost, time, quality and sustainability. After construction, the final product may attain the ICES objective, but not necessarily in the way initially established. Alternatively, the end product may not attain the $I C E S$ desired. Consequently it is necessary to assess the ICES throughout the project's life cycle in order to make decisions as appropriate.

Uncertainty is inherent to projects and it exists in respect of real, final ICES. Uncertainty can result in both opportunity and risk (del Caño, de la Cruz 2002). For example, potential changes in design or specification, such as those relating to the percentage of additions of fly ash or silica fume to concrete, can increase or decrease the final ICES. These and other changes could raise the sustainability index, for example, enabling the owner to obtain a higher sustainability certification, or higher subsidies where appropriate. The primary risk would be in the expenditure of specific funds to improve structural sustainability without attaining the ICES objective and thus sustainability certification and subsidies.

Corresponding author: Alfredo del Caño

E-mail: alfredo@udc.es 
Key stakeholders need to know how likely it is for the sustainability objective to be reached or exceeded at the end. A MIVES Monte Carlo simulation model (del Caño et al. 2012) is one option for taking the uncertainty of different sustainability parameters into account. The fuzzy method presented here is another.

\section{The MIVES method}

The first stages in the MIVES method consist of defining the problem to be solved and the decisions to be made, along with elaborating a basic decision-model diagram. This hierarchical diagram is denominated "requirement tree" and includes all aspects of the assessment to be made (Fig. 1). The lower part of the tree consists of the different qualitative and quantitative variables; the latter, in various units and scales. In the following stage, sustainability indicator magnitudes and units are converted into a common, non-dimensional unit called value. This method is based on Multi-Criteria Decision Methods (MCDM). To compare a specific design alternative to others, the existence of a value function $V: P \rightarrow R$ can be considered, where $P=\left(P_{1}, P_{2}, \ldots, P_{N}\right)$ is the set of evaluation indicators included in the requirement tree. A non-dimensional value function $V(P)$ integrating all the assessment indicators is then constructed. The solution is a non-dimensional function $V$ as the weighted sum of $N$ value functions $V_{i}$ corresponding to the $N$ indicators. MIVES uses Eqn (1) as the basis for defining individual value functions $V$ :

$$
V_{i}=\frac{1-e^{m_{i}\left(\frac{P_{i}}{n_{i}}\right)^{A_{i}}}}{1-e^{m_{i}\left(\frac{P_{i, \max }}{n_{i}}\right)^{A_{i}}} .}
$$

In this equation, $P_{i}$ is the score of the alternative being examined with respect to indicator $i$ under consideration, usually between 0 and 100. $P_{i, \max }$ is the maximum score that $P_{i}$ can reach, normally $100 . A_{i}, n_{i}$, and $m_{i}$ are shape factors used to generate concave, convex, "S" shape, or straight-line value functions. The $V_{i}$ functions' geometryconcave, convex and so on- makes it possible to consider non-linearity in the assessments, and also to establish greater or lesser exigency when complying with given indicator requisites (Alarcón et al. 2011). Finally, the Eqn (1) divisor ensures that value function remains within the range of $[0 ; 1]$, and that the highest contribution to sustainability is associated with a value equal to the unit.

In the next stage the relative weight of the model parameters is established $\left(\alpha_{i}, \beta_{i}\right.$ and $\gamma_{i}$ in Fig. 1). For problems based on a requirement tree with three levels, the resulting $V$ function takes the form of Eqn (2):

$$
V(P)=\sum_{i=1}^{i=N} \alpha_{i} \cdot \beta_{i} \cdot \gamma_{i} \cdot V_{i}\left(P_{i}\right)
$$

$V(P)$ measures the degree of sustainability for the alternative being assessed, with respect to indicators $P ; \alpha_{i}$ and $\beta_{i}$ are the requirement and criteria weights to which each indicator $i$ belongs; $\gamma_{i}$ are the different indicators weights; $V_{i}\left(P_{i}\right)$ are the value functions used to measure the degree of sustainability for the alternative under study with respect to a given indicator, $i$. Finally, $N$ is the total number of indicators taken into account for the assessment $(N=10$ in Fig. 1). Weights $\alpha_{i}, \beta_{i}$ and $\gamma_{i}$ are factors representing the preference or relevance, respectively, of certain indicators $\left(\gamma_{i}\right)$, criteria $\left(\beta_{i}\right)$ and requirements $\left(\alpha_{i}\right)$ against others.

Trees can at times be excessively large and complex. Discrepancies can also exist between specialists when establishing numerical values for $\alpha_{i}, \beta_{i}$, and $\gamma_{i}$. In these situations, the Analytic Hierarchy Process is used to organize the process in an efficient way, reducing complexity and subjectivity, assuring consistency and diminishing potential divergences among specialists. A final process for analysing, comparing, and, if appropriate, modifying resultant weights is recommended.

In the next stage the different design alternatives are evaluated using the previously created model. This makes it easier to reach decisions and choose the best design alternative. MIVES can be used to help decision makers in areas outside sustainable development. The reader can find additional information on, and a very detailed explanation of, the foundations of the MIVES method in Gómez et al. (2012).

\section{The ICES model}

The sustainability assessment model used here is based on EHE and incorporates several improvements developed by the authors to solve slight problems caused by small errors, misprints and omissions within the EHE text. In any case, both models produce similar results as the authors wished to respect the spirit of the EHE. The modifications alluded to lie outside the scope of this paper. However the reader can find the complete scope of these improvements in GRIDP (2012) (to be compared to Ministerio de la Presidencia (2008) and Ministerio de Fomento (2011)).

The sustainability assessment is structured in the usual environmental, social, and economic sections. Figure 1 comprises the improved environmental model requirement tree. The evaluation parameter is denominated as the Environmental Sustainability Index (ISMA, in Spanish) and fits in with Eqn (3), a specific Eqn (2) case for the problem being addressed here:

$$
I S M A=\sum_{i=1}^{i=10} \alpha_{i} \cdot \beta_{i} \cdot \gamma_{i} \cdot V_{i}
$$

Weights $\alpha_{i}, \beta_{i}$ and $\gamma_{i}$ (Fig. 1) differ from their EHE counterparts, although on the whole the influence of these various indicators on the ISMA is unaltered. With respect to the value functions of each indicator, all follow Eqn (1). On the other hand, the ISMA indicators in Figure 1 may have several quantitative and qualitative aspects to evaluate. There is therefore a fourth level of breakdown. Due to its length, this is included in Table 1. 


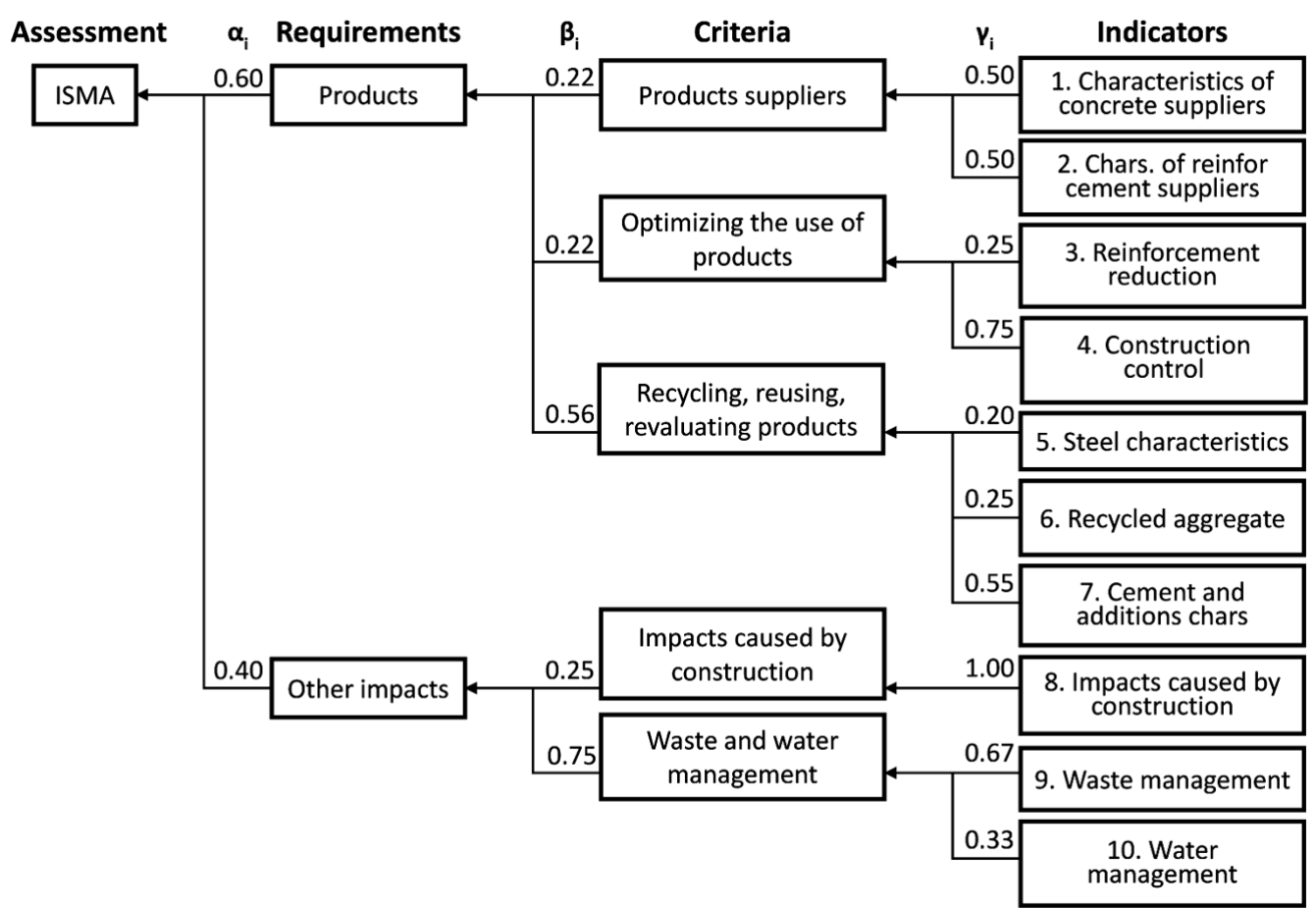

Fig. 1. Model requirement tree

To quantify the degree of compliance for all aspects under assessment, there is a scoring system for each indicator. As a result, a $P_{i}$ value is calculated for each indicator, and then introduced into the corresponding value function. This scoring system uses specific functions.

Different tables establish the scores for the possible design alternatives to be adopted for each indicator. The scoring system for the seventh indicator is summarized below, including its specific function and corresponding table (Table 2). This indicator is related to the characteristics of cement and additions. It helps evaluate the environmental contribution associated with the various aspects set out in the table. The specific function used for this purpose follows Eqn (4), where $p_{7 i}$ is the percentage of concrete produced with each type of cement, and $\lambda_{7 i}$ is the addition of the values included in the last column of Table 2, for each type of cement:

$$
p_{7}=\frac{1}{100} \cdot \sum_{i=1}^{i=n} p_{7 i} \cdot \lambda_{7 i}
$$

Table 1 summarizes the aspects taken into account in the scoring system for the other indicators. Where applicable, the design or construction alternatives resulting in a higher or lower score are shown in the table in parentheses. As for transport, a shorter distance means a higher score. Finally, in aspects expressed by percentages, the score increases with these percentages. The reader can find the complete EHE model in Spanish and English in Ministerio de la Presidencia (2008) and Ministerio de Fomento (2011), in addition to the modified model used here in GRIDP (2012).
Meanwhile, economic and social aspects are also taken into account to obtain an overall value for the ICES, using Eqn (5):

$$
\operatorname{ICES}=\mathrm{a}+\mathrm{b} \times \text { ISMA, }
$$

with the following restrictions:

$$
\begin{gathered}
I C E S \leq 1 ; \\
I C E S \leq 2 \times I S M A .
\end{gathered}
$$

In this equation, $a$ is the coefficient associated with the social contribution, which values the five issues reflected in Table 1 (variables 47 to 51 of Table 1). Economic aspects are taken into account using coefficient $b$, which increases with structural durability. Note that other economic aspects - such as material savings - have already been taken into account in the environmental indicators. Co-efficient $b$ is calculated using Eqn (6), dividing the estimated lifetime $\left(t_{g}\right)$ by the minimum compulsory lifetime required by $\operatorname{EHE}\left(t_{g, \mathrm{~min}}\right)$ :

$$
b=\frac{t_{g}}{t_{g, \min }} \leq 1.25 .
$$

A level scale has been established, similar to that used to compare appliance energy consumption. It gives each structure a sustainability level of A, B, C, D or E, depending on the numerical ICES obtained.

The EHE indicators are not the ones used in conventional life-cycle analysis (cLCA). The reality of the situation in many countries is that only a few professionals have enough knowledge and experience to perform 
Table 1. Model variables and their values in the case study. CS $=$ case study for Scenario \#1 of Table 3. $p=\left(p_{1}, p_{2}, p_{3}\right)=$ probability of (alternative1, alternative2, alternative3) for discrete variables. $\left(N_{1}, N_{2}, N_{3}\right)=$ (min, modal, max) values used to define fuzzy numbers

Indicator $\quad$ Model variables and their values in the case study

1. Origin of concrete (prefabrication company, external ready-mixed company, on-site facility). Case study (CS). $20 \%$ (volume) prefabricated elements supplied by two prefabrication companies $(18 \%$ for hollow core concrete floor slabs and $2 \%$ for stands). $80 \%$ concrete supplied by an external ready-mixed company.

Characteristics of 2. Environmental status of companies supplying concrete (certification, commitment, other cases). CS. Prefabrication company \#1 (18\% of total structure): $p=$ probability of (certification, commitment, other cases $)=(85 \%, 15 \%, 0 \%)$. Prefabrication company \#2 (2\% of total): certification. External ready-mixed company: $p=(60 \%, 20 \%, 20 \%)$.

concrete suppliers

3. Environmental status of contractor (certification, commitment, other cases). CS. $p=(85 \%, 15 \%, 0 \%)$.

4. Distances from concrete manufacturers' plants to site. CS. Prefabrication company \#1 (18\% of total): $($ minimum, modal value, maximum $)=(30,70,150) \mathrm{km}$. Prefabrication company $\# 2(2 \%$ of total $)$ : $780 \mathrm{~km}$. External ready-mixed company: $(8,20,45) \mathrm{km}$.

5. Reinforcement origin (prefabricated elements, external facility, on site facility). CS. 9\% (weight) prefabricated elements supplied by two prefabrication companies ( $8 \%$ for hollow-core concrete floor slabs and $1 \%$ for stands). $91 \%$ external facility.

Characteristics of reinforcement suppliers
6. Environmental status of rebar supplier (certification, commitment, other cases). CS. Prefabrication company \#1 ( $8 \%$ of total): $p=(85 \%, 15 \%, 0 \%)$. Prefabrication company \#2 (1\% of total): certification. External facility $(91 \%$ of total): $p=(85 \%, 15 \%, 0 \%)$.

7. Environmental status of contractor (certification, commitment, other cases). CS. $p=(85 \%, 15 \%, 0 \%)$.

8. Distances from rebar manufacturers plants to site. CS. Prefabrication company \#1 (8\% of total): (30, 70, $150) \mathrm{km}$. Prefabrication company \#2 (1\% of total): $780 \mathrm{~km}$. External facility: $(5,15,50) \mathrm{km}$.

9. Pre-stressed reinforcement (percentage). CS. 9\%.

Reinforcement reduction

10. Reinforcement with quality mark (percentage). CS. $0 \%$.

11. Rebar joined by mechanical means (not welded; percentage). CS. (10\%, 20\%, 40\%).

12. Steel with diminished safety coefficient, in accordance with EHE (percentage). CS. 9\%.

13. Concrete with diminished safety coefficient, in accordance with EHE (percentage). CS. 20\%.

14. Percentage of steel of each type. CS. $91 \%$ of B-500S and $9 \%$ of Y-1670 C.

15. Environmental certification of steel production (EMAS, ISO, nothing). CS. $p=(20 \%, 60 \%, 20 \%)$ for both types of steel.

16. Steel with quality mark (yes, no). CS. $\mathrm{p}=(85 \%, 15 \%)$ for both types.

Steel characteristics

17. Quality mark certifying that at least $80 \%$ of production uses recycled scrap (yes, no). CS. No.

18. Quality mark certifying steel production subject to Kyoto Protocol requirements (yes, no). CS. $p=(85 \%, 15 \%)$ for both types of steel.

19. Quality mark certifying that steel manufacturer makes use of more than $50 \%$ of steel slag (yes, no). CS. No.

20. Raw materials and steel subjected to radiological emission testing (yes, no). CS. No.

21. Concrete of each type (percentage) . CS. $80 \%$ of HA-30. $18 \%$ of HP-40. $2 \%$ of HP-45.

Recycled aggregate

22. Recycled aggregate (percentage). CS. $0 \%$ in all cases.

23. Concrete produced with each type of cement (percentage). CS. HA-30: CEM II, B-P 42,5 N (80\% of total concrete). HP-40: CEM II, B-V 52,5 R (18\% of total concrete). HP-45: CEM II, A-D 52,5 R ( $2 \%$ of total concrete).

24. Environmental certification of cement production (EMAS, ISO, nothing). CS. $p=(50 \%, 50 \%, 0 \%)$ for all cements.

Cement and additions characteristics
25. Cement with quality mark (yes, no). CS. Yes, in all cases.

26. Production subject to Kyoto Protocol requirements (yes, no). CS. $p=(85 \%, 15 \%)$ for all types of cement.

27. Quality mark certifying production of cements using fuels and raw materials generating lower $\mathrm{CO}_{2}$ emissions (yes, no). CS. No.

28. Types of additions (additions to the cement; additions to concrete; in cases of concrete with quality mark, produced by a company with environmental certification; other cases). CS. Additions to cement. 


\begin{tabular}{|c|c|}
\hline & $\begin{array}{l}\text { 29. Additions to the cement (percentage). CS. CEM II, A-B } 42,5 \mathrm{~N}:>20 \% \text {. CEM II, B-V 52,5 R: }>20 \% \text {. } \\
\text { CEM II, A-D 52,5 R: }<20 \% \text {. }\end{array}$ \\
\hline & 30. Additions of fly ash to concrete (percentage). CS. $0 \%$ in all cases. \\
\hline & 31. Additions of silica fume to concrete (percentage). CS. $0 \%$ in all cases. \\
\hline \multirow{6}{*}{$\begin{array}{l}\text { Impacts caused by } \\
\text { construction processes }\end{array}$} & 32. Site accesses paved (yes, no). CS. Yes. \\
\hline & 33. Pneumatic cleaning systems (yes, no). CS. No. \\
\hline & 34. Dust retention devices (yes, no). CS. $p=(50 \%, 50 \%)$. \\
\hline & s35. On-site sprinklers to avoid generating dust (yes, no). CS. $p=(15 \%, 85 \%)$. \\
\hline & 36. Chemical stabilizers to reduce dust production (yes, no). CS. No. \\
\hline & 37. Tarpaulin or canvas use during transport to cover material that can generate dust (yes, no). CS. Yes. \\
\hline \multirow{5}{*}{ Waste management } & $\begin{array}{l}\text { 38. Management of excavation products (recycling, reusing or revalorizing, dumping). CS. } 11 \% \text { reuse, } \\
89 \% \text { dumping. }\end{array}$ \\
\hline & $\begin{array}{l}\text { 39. Management of construction and demolition waste (recycling, reusing or revalorizing, dumping). CS. } \\
\text { Dumping. }\end{array}$ \\
\hline & 40. Concrete with quality mark (percentage). CS. $0 \%$. \\
\hline & 41. Cylindrical specimens without sulfur capping, for testing concrete (percentage). CS. $0 \%$. \\
\hline & 42. Cubic specimens for testing concrete (percentage). CS. $0 \%$. \\
\hline \multirow{4}{*}{ Water management } & 43. Contractor's environmental status (certification, commitment, other cases). CS. $p=(85 \%, 15 \%, 0 \%)$. \\
\hline & 44. Efficient curing techniques in respect of water consumption (yes, no). CS. $p=(85 \%, 15 \%)$. \\
\hline & 45. Water saving devices (yes, no). CS. No. \\
\hline & 46. Containers for collection and use of rain water (yes, no). CS. No. \\
\hline \multirow{5}{*}{ Social contribution } & $\begin{array}{l}\text { 47. Application of innovative design or construction methods deriving from R\&D and innovation } \\
\text { projects (yes, no). CS. No. }\end{array}$ \\
\hline & 48. On-site staff training in excess of legal requirements (yes, no). CS. Yes. \\
\hline & $\begin{array}{l}\text { 49. Adopting voluntary health and safety measures in excess of legal requirements (yes, no). CS. } \\
p=(15 \%, 85 \%) \text {. }\end{array}$ \\
\hline & $\begin{array}{l}\text { 50. Establishing measures informing the public of the features and timescales, in addition to the } \\
\text { economic and social implications of the project (yes, no). CS. No. }\end{array}$ \\
\hline & 51. Having the project declared of public interest by the Administration (yes, no). CS. No. \\
\hline \multirow{2}{*}{$\begin{array}{l}\text { Extended lifetime } \\
\text { contribution }\end{array}$} & 52. Minimum lifetime established by EHE for this type of structure. CS. 100 years. \\
\hline & 53. Structure's estimated lifetime. CS. 100 years. \\
\hline
\end{tabular}

cLCA. On the contrary, the EHE method is easier for practitioners to understand and apply.

\section{The Fuzzy-MIVES-EHEm method}

\subsection{Foundations}

Fuzzy sets theory solves a broad range of problems. One application has to do with uncertainty. Various authors have dealt with fuzzy sets and their application in the analysis or control of processes and physical systems, as well as decision making. In the field of project uncertainty, many authors have applied fuzzy sets to project selection; the financial analysis of the project; time and cost estimation and control; contractor selection and risk analysis (see, for instance, Zadeh et al. 1975; Kaufmann, Gupta 1985, 1991; Carr, Tah 2001; Li et al. 2007; Gil-Aluja 2010; Abbasianjahromi, Rajaie 2012).

The method presented here is based on establishing fuzzy sets for input variables affected by a relevant uncertainty, and using fuzzy arithmetic for calculating a global fuzzy sustainability index. Fuzzy sets were established as an extension of the conventional, crisp sets, to build models incorporating the imprecision or vagueness of many human concepts.

An element can only have two membership values in relation to a crisp set: 1 and 0 , depending on whether or not it belongs to the crisp set. This is the case with the set of distances between 0 and $30 \mathrm{~km}$. On the other hand, the membership function $\mu(x)$ of an element to a fuzzy set can take any value in $[0,1]$. This happens with a potential set of "short" distances.

If $U$ is a universal set, the fuzzy subset $A$ of $U$ is defined by its membership function $\mu_{A}: U \rightarrow[0,1]$, assigning a real number $\mu_{A}(x)$ in the interval $[0,1]$, to each element $x \in U$, where the value of $\mu_{A}(x)$ at $x$ shows the degree of membership of $x$ in $A$. So $A=\left\{\left(x, \mu_{A}(x)\right): x \in U, \mu_{A}(x) \in\right.$ $[0,1]\}$. In a crisp set $\mu_{A}(x)=1$ if $x \in A$, and $\mu_{A}(x)=0$ if $x \notin A$.

Given a fuzzy set $A$ in $U$ and any real number $\alpha \in[0,1]$, then an alpha-cut of $A$ is the crisp set ${ }^{\alpha} A=\{x \in U$ : $\left.\mu_{A}(x) \geq \alpha\right\}, \alpha \in[0,1]$ (see Fig. 2a). The family including 
Table 2. Aspects evaluated via seventh environmental indicator from model

\begin{tabular}{|c|c|c|}
\hline \multicolumn{2}{|c|}{ Characteristics of cement and additions } & $\lambda_{7 \mathrm{i}}$ \\
\hline \multirow{2}{*}{$\begin{array}{l}\text { Environ- } \\
\text { mental cer- } \\
\text { tification of } \\
\text { production }\end{array}$} & ISO 14001 (2004) & 10 \\
\hline & EMAS (2013) & 15 \\
\hline $\begin{array}{l}\text { Kyoto } \\
\text { Protocol }\end{array}$ & $\begin{array}{l}\text { Official quality mark certifying } \\
\text { that cement production is } \\
\text { subject to Kyoto Protocol } \\
\text { requirements. }\end{array}$ & 20 \\
\hline $\begin{array}{l}\text { Reducing } \\
\mathrm{CO}_{2} \\
\text { emissions or } \\
\text { using waste } \\
\text { materials as } \\
\text { fuel. }\end{array}$ & $\begin{array}{l}\text { Official quality mark certifying } \\
\text { a cement production using fuels } \\
\text { or raw materials producing } \\
\text { lower } \mathrm{CO}_{2} \text { emissions; or } \\
\text { employing alternative (non- } \\
\text { fossil) fuels; or using waste } \\
\text { materials as fuels. }\end{array}$ & 15 \\
\hline \multirow{3}{*}{$\begin{array}{l}\text { Additions' } \\
\text { content }\end{array}$} & $\begin{array}{l}\text { Cement does not contain } \\
\text { additions, but concrete includes } \\
\text { fly ash or silica fume additions. } \\
\text { Moreover the concrete } \\
\text { has a quality mark and is } \\
\text { produced by a company with } \\
\text { environmental certification. }\end{array}$ & $\begin{array}{l}0-30 \text { for fly ash } \\
\text { or silica fume, } \\
\text { respectively, } \\
\text { between } 0-35 \% \\
\text { and } 0-12 \% \\
\text { ( } \% \text { of cement } \\
\text { weight). }\end{array}$ \\
\hline & $\begin{array}{l}\text { Cement contains additions } \\
\text { compliant with extant } \\
\text { legislation and concrete has } \\
\text { a quality mark. Percentage of } \\
\text { additions } \leq 20 \% \text {. }\end{array}$ & 35 \\
\hline & $\begin{array}{l}\text { As above but with an additions } \\
\text { percentage }>20 \% \text {. }\end{array}$ & 50 \\
\hline
\end{tabular}

all the alpha-cuts of a fuzzy set contains all the information relative to that set.

On the other hand, a fuzzy set is convex if $\mu_{A}(\lambda \mathrm{x}+$ $(1-\lambda) \times y) \geq \min \left\{\mu_{A}(x), \mu_{A}(y)\right\}, \forall x, y \in U$ and $\forall \lambda \in[0,1]$. Thus, the concept of convexity here is similar to the one related to a conventional function $y=f(x)$.

Finally, a fuzzy number is a convex, normalized fuzzy set of real line $R$ with a piecewise, continuous membership function, where there is at least an $M \in R$ point, with $\mu_{A}(M)=1\left({ }^{\alpha=1} A=M\right)$. Fuzzy numbers can have different geometric shapes, reflecting actual circumstances.
In the model presented here, a continuous input variable is represented by a triangular fuzzy number (Fig. 2a). On the other hand, a discrete input variable is represented by a specific discrete fuzzy set explained here (Fig. 2b). For example, one model input variable referred to above (Table 2) relates to the environmental certification of cement production. The scoring corresponding to this variable is $(15,10,0)$, for (EMAS certificate (European Parliament, Council of the European Union 2013), ISO-14001 certificate (2004), other cases) respectively.

If one assumes that the engineer conducting the assessment of a specific structure considers the (EMAS, ISO, other cases) probabilities to be $(40 \%, 60 \%, 0 \%)$ (Fig. 2b), the corresponding probability histogram can be converted into a discrete fuzzy set. Using a fuzzy set of three values $(15,10,0)$ with membership values $(0.4 ; 0.6 ; 0)$ implies that there is not an alpha-cut corresponding to a membership value of 1 . A solution is to normalize the fuzzy set of the discrete variable; other methods have been explored, but only this one produced sound results. Thus the fuzzy set to be used in calculations will have the same values $(15,10,0)$, but now with membership values $(0.67 ; 1 ; 0)$ (Fig. 2b). Finally, a deterministic variable will be represented as a singleton. This is a fuzzy number that represents a crisp one: it only takes the value of the crisp number, with a membership value of 1 .

Following on, a first possibility is to perform fuzzy operations with different input variables, applying the Zadeh Extension Principle (Zadeh 1975a, 1975b, 1975c). In this case there are several discrete variables, however (Table 1). Operating with continuous and discrete variables will result in very cumbersome calculations, and is frequently unfeasible. This will not occur where all fuzzy input variables are continuous.

There are other possibilities using simplified, approximate methods. The main ones are the Vertex and DSW methods (Ross 2010). The most suitable of these is the second one (DSW, from Dong, Shah, and Wong) (Dong et al. 1985), based on performing interval operations with alpha-cuts. With this method, in order to operate two variables, it is necessary to calculate several
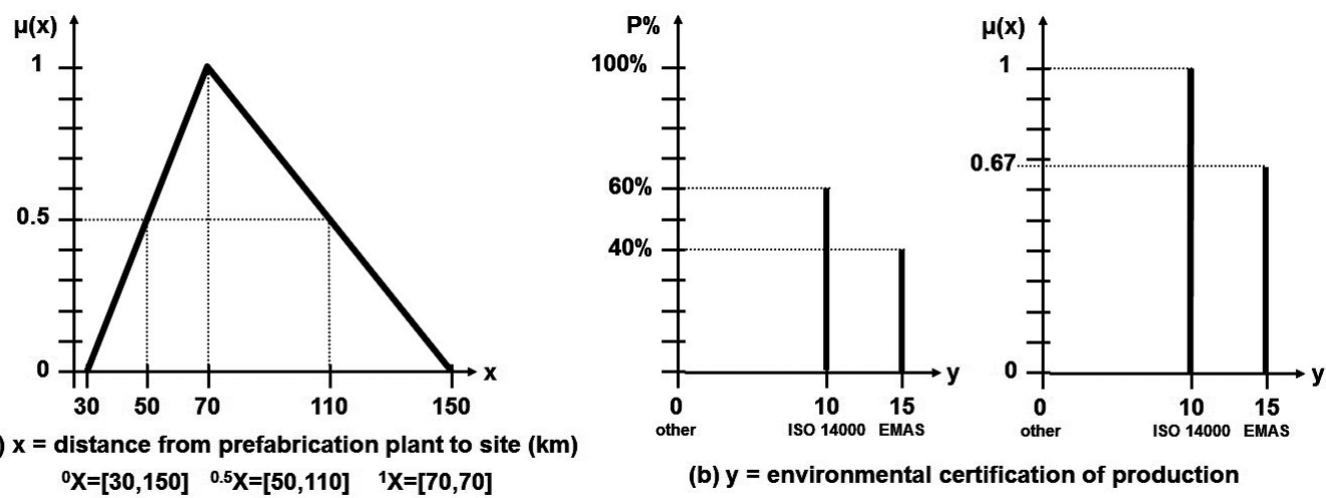

(b) $y=$ environmental certification of production

Fig. 2. Examle of fuzzy paramaters 
alpha-cuts for each one. An alpha-cut constitutes an interval. Consequently both pairs of values belonging to each alpha-cut will be operated using interval arithmetic (Ross 2010). MIVES only uses positive values, since $V_{i}$ (Eqn (1)) can only take values in $[0,1]$. Suppose two intervals $I_{1}=[a, b]$ and $I_{2}=[c, d]\left(a, b, c, d \in R^{+}, a \leq b\right.$, $c \leq d)$. The interval operations needed for MIVES models (Eqns (1) to (6)) are:

$$
\begin{gathered}
I_{1}+I_{2}=[a+c, b+d] ; \\
I_{1}-I_{2}=[a-d, b-c],(a \geq d, b \geq c) ; \\
I_{1} \times I_{2}=[a \times c, b \times d] ; \\
I_{1} \div I_{2}=[a \div d, b \div c], I_{2} \in R 0^{+}\left(R^{+}, \text {excluding zero }\right) ; \\
e^{\mathrm{I1}}=\left[e^{a}, e^{b}\right] ; \\
I_{1}{ }^{\mathrm{I}}=\left[a^{c}, b^{d}\right] .
\end{gathered}
$$

Consequently, in order to calculate the addition of two fuzzy numbers, the alpha-cut corresponding to a membership value of $1\left({ }^{\alpha=1} X\right)$ is calculated for both numbers (Fig. 2a).

Subsequently, the minimum value of the alpha-cut for the first number is added to the minimum value of the alpha-cut for the second number. Similarly, the maximum value of the alpha-cut for the first number is added to the maximum value of the alpha-cut for the second number. The alpha-cuts corresponding to a membership value of $0.9\left({ }^{\alpha=0.9} X\right)$ will then be added up, and so on.

This generates an alpha-cut set corresponding to the fuzzy number that is the result of the fuzzy operation under calculation, and serves in generating the resulting number. This is a summary of the computational way of implementing such calculations, but the reader can find additional information on it in Appendix I of this paper.

It is essential that the fuzzy variables have values adjusted to the model's actual behaviour. At least key value estimates must be realistic: for instance, the alphacut for $\alpha=0$ (maximum, minimum) and the alpha-cut for $\alpha=1$ (Fig. 2a). There are no databases containing historical data for the parameters evaluated here. Consequently, just as triangular distributions are recommended for simulation purposes in this case (Williams 1992), for continuous numerical variables triangular fuzzy numbers are recommended. They are simple to understand and easy to estimate as they only require an estimate of extreme $\left({ }^{\alpha=0} X\right)$ and "most possible" values $\left({ }^{\alpha=1} X\right)$.

Furthermore, they can be configured as asymmetric. This is a necessary characteristic here as the distances between the "most possible" and the two extreme values of the number usually differ. Finally, the most likely (modal) value can be used as the "most possible" value of the fuzzy number $\left({ }^{\alpha=1} X\right)$. This will make things easier, since, due to human mind characteristics, modal (repetitive) values are easily stored mentally in day-to-day life.

It is not crucial whether the geometry of these fuzzy numbers adjusts perfectly to potentially real facts. If the estimates for key parameters are reliable, it is better to apply the method presented here, or others based on simulation, rather than depending on mere crisp, deterministic models. Non-deterministic methods deal with the complexity of reality better.

\subsection{Stages}

Project uncertainty makes estimating the ICES and managing the structural sustainability objective difficult. A hybrid method based on the MIVES method and fuzzy arithmetic has been designed to solve this. This shall now be referred to as Fuzzy-MIVES-EHEm. It makes it easier to manage the sustainability objective for a concrete structure in accordance with the assessment model found in Section 2. However, uncertainty must now be taken into account.

The first stage (Stage S1; Fig. 3) involves selecting the input parameters that can be affected by a relevant uncertainty (fuzzy inputs). There are always inputs that have a higher degree of uncertainty than others and some variables have a greater influence than others on model results. It is recommended that only those inputs with the greatest influence over the model and a significantly high degree of uncertainty are established as fuzzy. For further information about this, see del Caño et al. (2012).

On the other hand, the uncertainty of each variable can change throughout the project life-cycle. Normally it decreases, but specific project changes can bring uncertainty to a variable that previously seemed certain. The analyst should decide in each case and, at every moment, which variables are fuzzy inputs.

Once the first stage has been completed, the next step is to estimate the values that the model inputs take (Stage S2). The following phase (Stage S3) consists of performing the previously summarized fuzzy calculations in order to obtain the fuzzy ICES. This stage also includes performing defuzzification, converting that fuzzy index into a set of crisp parameters that the designer can easily understand. Those parameters are analyzed by

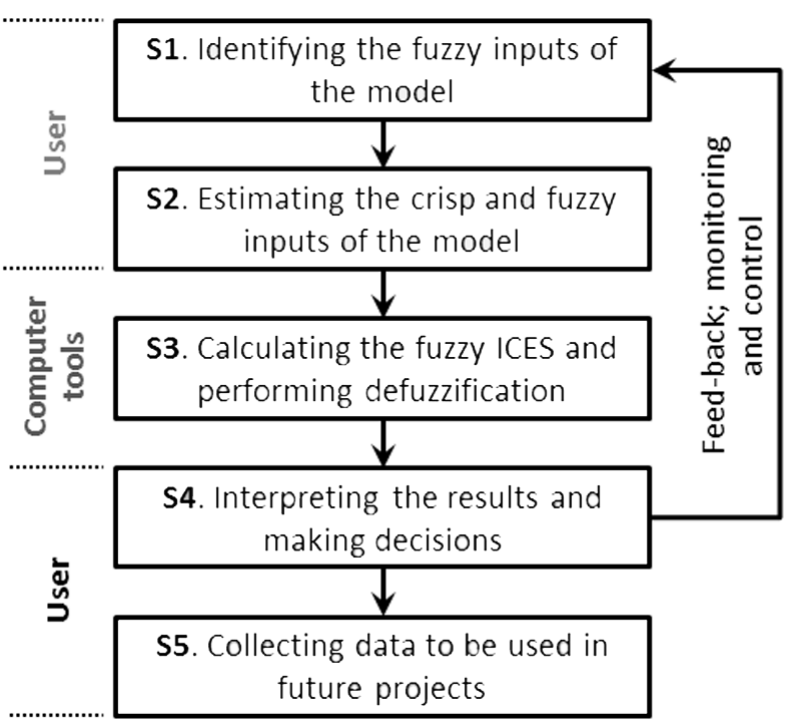

Fig. 3. Fuzzy-MIVES-EHEm method flowchart 
the user in the next phase (Stage S4), and the relevant decisions are made.

Phases S1 to S4 are performed on a periodic basis throughout the project's life cycle and whenever there are major project changes. Continuous information collection will assist the user in managing the sustainability objective throughout the project's entire life cycle.

The final stage (Stage S5) is absolutely crucial. It is essential to compile actual final data, thus generating an historical database. This will make it possible in the future to perfect the model and estimate its input variables more effectively. This could mean using fuzzy numbers with other shapes different from the triangular one suggested here, but the method presented in this paper is applicable to any kind of fuzzy numbers. As a result of the application of this final stage in different projects, ICES estimation and uncertainty management will increasingly improve in efficiency and effectiveness.

\subsection{Defuzzification: parameters generated for help in decision making}

After performing all the calculations mentioned in Section 3.1, a final result will be obtained in the form of an ICES fuzzy number. The fuzzy number graph could be shown directly to the user, but a defuzzification process must be performed to better assist decision makers. In our case the ICES will be a fuzzy number different to triangular and trapezoidal ones, made up of segments and with a shape similar to the probability histogram obtained through simulation (Fig. 4). Several values can be highlighted to the user. The most obvious are the minimum and maximum potential ICES $\left({ }^{\alpha=0}\right.$ ICES $)$. Moreover, the range of values corresponding to ${ }^{\alpha=1} I C E S$ can be called the "range of most possible" ICES values. This can be complemented with the central value of this range.

On the other hand, specific parameters will serve to give the user an idea of the effect of uncertainty on the potential final, real ICES, and thus about the risk of not meeting the established sustainability objective. This will help in subsequent decision making. The authors suggest using the following parameters, with similarities to specific ones resulting from a Monte Carlo simulation:

- The difference between the minimum and maximum potential ICES $\left({ }^{\alpha=0} I C E S\right)$ : the ICES range.

- The area of the fuzzy ICES $\left(A_{\text {ICES }}\right)$.

- The average of the differences between the gravity centre of the several segments of the fuzzy ICES (ICESgc $i$, for $i=1$ to the $n$ segments) and its global gravity centre $I C E S_{G C}$. This parameter can be called the variance of the fuzzy number $(\operatorname{Var} F N)$ : $\operatorname{Var} F N=$ $\left[\left(I C E S g c_{1}-I C E S_{G C}\right)^{2}+\left(I C E S g c_{2}-I C E S_{G C}\right)^{2}+\ldots+\right.$ $\left.\left(I C E S g c_{n}-I C E S_{G C}\right)^{2}\right] / n$.

- The square root of $\operatorname{VarFN}(\operatorname{SigmaFN})$.

Finally, there are another two interesting parameters. The first is the ICES that leaves $95 \%$ of the fuzzy ICES area on its right $\left(I C E S_{A 95 \%}\right)$. This is a conservative value similar to the ICES value corresponding to a $95 \%$ confidence level, resulting from simulation. The other is the possibility of reaching a specific ICES level. This is calculated as the quotient between the area to the right side of the objective ICES and the total area $\left(A_{I C E S}\right)$ of the fuzzy ICES, expressed as a percentage: $\operatorname{Pos}(I C E S \geq$ $\left.I C E S_{o b j}\right)=A_{\text {right }}\left(I C E S_{\text {obj }}\right) / A_{\text {ICES }}$.

Despite the resemblance between the fuzzy ICES and the probability histograms obtained with Monte Carlo simulation, the defuzzification parameters mentioned are not the same as their probabilistic counterparts: modal interval and ${ }^{\alpha=1} I C E S$; average and $I C E S_{G C}$; variance and $\operatorname{VarFN}$; standard deviation and SigmaFN; 95\% confidence and $I C E S_{A 95 \%} ; \mathrm{P}\left(I C E S \geq I C E S_{o b j}\right)$ and $\operatorname{Pos}\left(I C E S \geq I C E S_{o b j}\right)$ (probability and possibility). Nevertheless, those defuzzification parameters will normally adopt values consistent of, coherent with and close to those resulting from the simulation method. This will now be seen.

\section{Case study}

In this section, the method outlined here is applied to a case study. The results are compared to those obtained from applying to the same case a Monte Carlo simulation method conceived for the same purpose (del Caño et al. 2012). This relates to a Sports Centre located in Galicia (North-West Spain) with a surface area of more than $15,000 \mathrm{~m}^{2}$. The roof sits on steel trusses and the rest of the structure is made of concrete.

The building has structural elements of reinforced, on-site poured concrete (foundations, columns, and beams) and pre-stressed precast concrete (stands and floor slabs), totalling $11,297 \mathrm{~m}^{3}$ of concrete and $902 \mathrm{t}$ of steel reinforcement. Other concrete structure characteristics are summarized in Table 1. This table also provides the information required to perform the corresponding Fuzzy-MIVES-EHEm calculations.

After applying the method, the resulting fuzzy ICES can be seen in Figure 4 (on the left). The potential ICES values at the end of the project can range from 0.25 to $0.51\left({ }^{\alpha=0}\right.$ ICES $)$, corresponding to levels $\mathrm{D}$ and $\mathrm{C}$ of ICES. Most possible values should be within the [0.43, $0.45]$ interval $\left({ }^{\alpha}=1\right.$ ICES; level C). On the other hand,

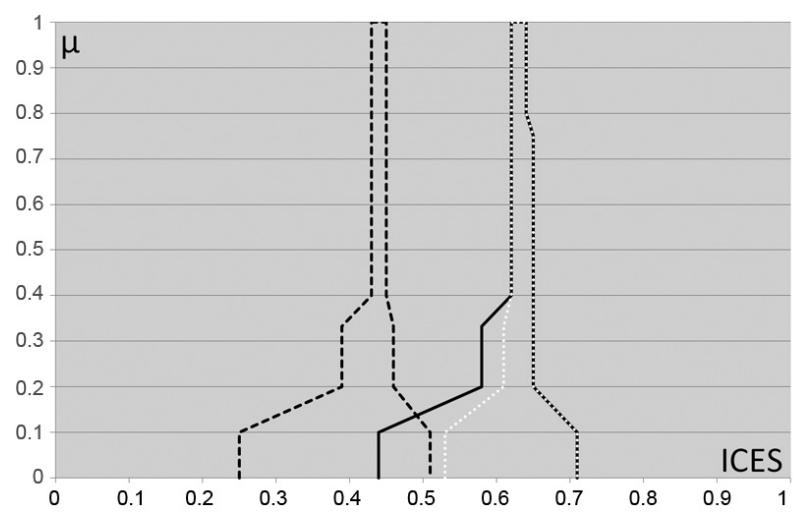

Fig. 4. Case study: fuzzy ICES for the three scenarios 
SigmaFN $=0.051, I C E S_{A 95 \%}=0.28$ (level D), and Pos $($ ICES level $\geq \mathrm{B})=0$. Applying the simulation method, extreme values are 0.30 and 0.51 (D and $C$ levels), the probabilistic modal interval is [0.40-0.50], standard deviation $=0.33, \mathrm{P}(I C E S$ level $\geq \mathrm{B})=0$, and with a $95 \%$ confidence level, the ICES for this structure exceeds 0.36 (level D). As can be seen, the probabilistic parameters are close to those obtained with the fuzzy method.

Scenario \#1 of Table 3 summarizes this situation. The reader should take into account that the distribution functions used in the simulation model are not closed, triangular ones. Rather, they are trigen distributions (open ones; Hillson, Simon 2007) leaving a 5\% probability of exceeding extreme values included in Table 1. This assumes that the user may make small errors when estimating extreme values.

Looking at Table 3, it is evident that significant changes must be made in order to achieve a relevant possibility of attaining a desirable sustainability objective. Potential ICES, for instance, could be raised, thus increasing the values for variables 12 (from $9 \%$ to $100 \%$; Table 1), 38 (now $85 \%$ and $15 \%$, respectively, for re-use and dumping) and 39 (now $75 \%$ for recycling and 15\% for dumping). The new fuzzy ICES is depicted in Figure 4 (continuous line). The results of applying both methods are contained in Table 3 (Scenario \#2). Once again these are close. Minimum, maximum, modal and most possible values have now been increased. Either way, the possibility of attaining a $\mathrm{B}$ or higher level is not high. On the other hand, the modifications undertaken only affect deterministic, crisp inputs. As a result, the level of uncertainty remains the same. Obviously, it is possible to increase potential ICES, thus diminishing uncertainty in some specific inputs.

Ensuring that the different companies involved have environmental certification, for instance, will affect inputs 2, 3, 6, 7 and 43 of Table 1 and the possibility of attaining a B level will be enhanced. The third fuzzy ICES is shown in Figure 4 (white dotted line). The results from applying both methods are included in Table 3
(Scenario \#3) and again are similar. Modal intervals and $\alpha={ }^{1}$ ICES retain the same values, but the uncertainty level is now lower and the likelihood of achieving a B or higher level is high.

Table 3 also includes the results from applying the deterministic EHE model, calculated using the most frequent values for the input parameters. This is the most common way of proceeding when using deterministic methods. As can be seen in Table 3, the fuzzy method is generally more conservative than the one based on simulation. On the other hand, the deterministic method does not give the user enough information to make adequate decisions.

\section{Conclusions}

It is now increasingly more common to set project sustainability objectives, and not just in the construction sector. Uncertainty, on the other hand, poses a problem in estimating sustainability, especially in early project phases. The potential effectiveness of the sustainability management function is diminished and it is therefore much less probable that the corresponding objective is achieved. This makes it more difficult to apply deterministic, crisp assessment systems.

A probabilistic MIVES model is a potential solution to this problem. The fuzzy method presented here is another one. Both methods help designers and project managers to compare the consequences of making different decisions. They facilitate on-time decision making in order to achieve the sustainability objective. Moreover, they can be applied to other structural sustainability codes and models, as well as other system sustainability models (facades, heating systems, buildings, civil engineering systems). Nevertheless, they are particularly suited to large and complex projects.

To apply these methods it is necessary to develop computer tools that usually cannot be designed or constructed by an architect or structural engineer. Programming such methods should not prove to be too dif-

Table 3. Case study: results and comparison with the deterministic and simulation methods

\begin{tabular}{|c|c|c|c|c|c|c|c|}
\hline \multicolumn{2}{|c|}{ Method/ICES parameters } & \multicolumn{2}{|c|}{ Scenario \#1 } & \multicolumn{2}{|c|}{ Scenario \#2 } & \multicolumn{2}{|c|}{ Scenario \#3 } \\
\hline \multicolumn{2}{|c|}{ EHE model (deterministic ICES) } & \multicolumn{2}{|c|}{0.43} & \multicolumn{2}{|c|}{0.62} & \multicolumn{2}{|c|}{0.62} \\
\hline Monte Carlo & Fuzzy & Monte Carlo & Fuzzy & Monte Carlo & Fuzzy & Monte Carlo & Fuzzy \\
\hline Minimum & $\alpha={ }^{0} \mathrm{ICES}$ & $\begin{array}{c}0.30 \\
\text { (level D) }\end{array}$ & 0.25 (D) & $0.49(\mathrm{C})$ & $0.44(\mathrm{C})$ & $0.55(\mathrm{C})$ & $0.53(\mathrm{C})$ \\
\hline Maximum & & $0.51(\mathrm{C})$ & $0.51(\mathrm{C})$ & $0.70(\mathrm{~B})$ & $0.71(\mathrm{~B})$ & $0.70(\mathrm{~B})$ & $0.71(\mathrm{~B})$ \\
\hline Modal interval & $\alpha=1$ ICES & $\begin{array}{c}{[0.40-0.50]} \\
\text { (level C) }\end{array}$ & $\begin{array}{c}{[0.43,0.45]} \\
\text { (level C) }\end{array}$ & $\begin{array}{c}{[0.60-0.70]} \\
\text { (level B) }\end{array}$ & $\begin{array}{c}{[0.62,0.64]} \\
\text { (level B) }\end{array}$ & $\begin{array}{c}{[0.60-0.70]} \\
\text { (level B) }\end{array}$ & $\begin{array}{c}{[0.62,0.64]} \\
\text { (level B) }\end{array}$ \\
\hline Distribution range & Range of ${ }^{\alpha}=0$ ICES & 0.21 & 0.26 & 0.21 & 0.27 & 0.15 & 0.18 \\
\hline Standard deviation & SigmaFN & 0.033 & 0.051 & 0.033 & 0.051 & 0.027 & 0.041 \\
\hline $95 \%$ confidence & $\mathrm{ICES}_{\mathrm{A} 95 \%}$ & $\begin{array}{c}0.36 \\
\text { (level D) }\end{array}$ & 0.28 (D) & $0.55(\mathrm{C})$ & $0.47(\mathrm{C})$ & $0.59(\mathrm{C})$ & $0.55(\mathrm{C})$ \\
\hline $\begin{array}{l}\text { Probability } \\
\text { (ICES } \geq \text { B) }\end{array}$ & Pos $($ ICES $\geq B)$ & $0 \%$ & $0 \%$ & $63 \%$ & $56 \%$ & $85 \%$ & $77 \%$ \\
\hline
\end{tabular}


ficult for a software engineer or a structural engineer accustomed to such work. The methods are relatively easy to develop and implement.

In particular, that of using fuzzy arithmetic instead of simulation has specific pros and cons. On the one hand, this method is less complex and implies fewer calculations than the one based on simulation. It makes programming the corresponding algorithm process easier and offers a real advantage in computation time. The computational time and cost can be divided by 25 to 250 , depending on the model size.

Additionally, the authors consider that the method proposed here could be understood more easily or at least more speedily by practitioners. On the other hand, this method produces less profuse result parameters than those generated by simulation. Nevertheless, the practitioner has a very complete set of parameters to help with decision making. In the authors' opinion, the fuzzy method could be a better solution in specific cases of limited time or budget for creating the model. The simulation-based method can be used in other cases.

\section{Acknowledgements}

This study has been conducted within the framework of two projects funded by the Xunta de Galicia (Galician regional government; project code 08TMT011166PR), and the Spanish Ministry for Science and Innovation (project code BIA2010-20789-C04-02), respectively. The authors are also grateful to Profs. Alberto Bugarín (University of Santiago de Compostela, Spain), and Ricardo Bendaña (University of Vigo, Spain), for several interesting conversations that helped them in their work.

\section{References}

Abbasianjahromi, H.; Rajaie, H. 2012. Developing a project portfolio selection model for contractor firms considering the risk factor, Journal of Civil Engineering and Management 18(6): 879-889. http://dx.doi.org/10.3846/13923730.2012.734856

Aguado, A.; del Caño, A.; de la Cruz, M. P.; Gómez, D.; Josa, A. 2012. Sustainability assessment of concrete structures within the Spanish structural concrete code, Journal of Construction Engineering and Management 138(2): 268-276. http://dx.doi.org/10.1061/(ASCE)CO.1943-7862.0000419

Alarcón, B.; Aguado, A.; Manga, R.; Josa, A. 2011. A value function for assessing sustainability: application to industrial buildings, Sustainability 3: 35-50. http://dx.doi.org/10.3390/su3010035

Carr, V.; Tah, J. H. M. 2001. A fuzzy approach to construction project risk assessment and analysis: construction project risk management system, Advances in Engineering Software 32(10-11): 847-857. http://dx.doi.org/10.1016/S0965-9978(01)00036-9

Cuadrado, J.; Roji, E.; San Jose, J. T.; Reyes, J. P. 2012. Sustainability index for industrial buildings, Proceedings of the Institution of Civil Engineers - Structures and Buildings 165(5): 245-253. http://dx.doi.org/10.1680/stbu.10.00029

del Caño, A.; de la Cruz, M. P. 2002. Integrated methodology for project risk management, Journal of Construction
Engineering and Management 128(6): 473-485.

http://dx.doi.org/10.106 1/(ASCE)0733-9364(2002)128:6(473)

del Caño, A.; Gómez, D.; de la Cruz, M. P. 2012. Uncertainty analysis in the sustainable design of concrete structures: a probabilistic method, Construction and Building $\mathrm{Ma}$ terials 37: 865-873.

http://dx.doi.org/10.1016/j.conbuildmat.2012.04.020

Dong, W.; Shah, H.; Wong, F. 1985. Fuzzy computations in risk and decision analysis, Civil Engineering and Environmental Systems 2(4): 201-208.

http://dx.doi.org/10.1080/02630258508970407

European Parliament, Council of the European Union. 2013. Regulation (EC) No 1221/2009 of the European Parliament and of the Council of 25 November 2009 on the voluntary participation by organisations in a Community eco-management and audit scheme (EMAS). Document 2009R1221-EN-01.07.2013-001.001. Eur-Lex. Brussels [online], [cited 14 April 2014]. Available from Internet: http://eur-lex.europa.eu/legal-content/EN/TXT/ PDF/?uri=CELEX:02009R1221-20130701\&qid=139747 $5928291 \&$ from $=\mathrm{EN}$

Gil-Aluja, J. 2010. Fuzzy Sets in the management of uncertainty. Heidelberg: Springer. $420 \mathrm{p}$.

Gómez, D.; del Caño, A.; de la Cruz, M. P.; Josa, A. 2012. Metodología genérica para la evaluación de la sostenibilidad de sistemas constructivos - El método MIVES, in A. Aguado (Ed.). Sostenibilidad y construcción. ACHE (Asociación Científico-Técnica del Hormigón), Madrid, Spain, 385-411 (in Spanish).

GRIDP 2012. Web with documents and publications of the Grupo de Ingeniería y Dirección de Proyectos of the University of La Coruña [online], [cited July 2013]. Available from Internet:

http://www.ii.udc.es/GRIDP/castellano/documentos.html

Hillson, D.; Simon, P. 2007. Practical project risk management: the atom methodology. Management Concepts. Vienna, VA, USA. $241 \mathrm{p}$.

ISO. 2004. ISO 14001:2004 Environmental management systems - Requirements with guidance for use. International Organization for Standardization. Geneva [online], [cited 14 April 2014]. Available from Internet:

http://www.iso.org/iso/catalogue_detail?csnumber=31807

Kaufmann, A.; Gupta M. M. 1985. Introduction to fuzzy arithmetic: theory and applications. New York: Van Nostrand Reinhold. $351 \mathrm{p}$.

Kaufmann, M.; Gupta, M. M 1991. Fuzzy mathematical models in engineering and management science. Amsterdam: North-Holland. 338 p.

Li, Y.; Nie, X.; Cheng., S. 2007. Fuzzy approach to prequalifying construction contractors, Journal of Construction Engineering and Management 133(1): 40-49.

http://dx.doi.org/10.1061/(ASCE)0733-9364(2007)133:1(40)

Ministerio de Fomento. 2011. Appendix 13. Structure's contribution to sustainability index. Translation to English of the reference Ministerio de la Presidencia (2008) [online], [cited October 2011]. Available from Internet: http://www. fomento.gob.es/NR/rdonlyres/50D89600-4877-40C0B70C-D4FCEBC24993/97107/Annex 13.pdf

Ministerio de la Presidencia 2008. Real Decreto 1247/2008, de 18 de julio, por el que se aprueba la instrucción de hormigón estructural (EHE-2008). Boletín Oficial del Estado (BOE); 203, de 22 de agosto de 2008. Spanish Government. Madrid [online], [cited 14 April 2014]. Available from Internet: http://www.boe.es/boe/dias/2008/08/22/ pdfs/C00001-00304.pdf, 239-247 (in Spanish).

Pons, O.; Aguado, A. 2012. Integrated value model for sustainable assessment applied to technologies used to build schools in Catalonia, Spain, Building and Environment 53: 49-58. http://dx.doi.org/10.1016/j.buildenv.2012.01.007 
Reyes, J. P.; San-José, J. T.; Cuadrado, J.; Sancibrian, R. 2014. Health \& Safety criteria for determining the sustainable value of construction projects, Safety Science 62: 221-232. http://dx.doi.org/10.1016/j.ssci.2013.08.023.

Ross, T. J. 2010. Fuzzy logic with engineering applications. Chichester: John Wiley. 585 p.

Saaty, T. L. 1980. The analytic hierarchy process. New York: McGraw-Hill. 287 p.

Saaty, T. L. 2006. Fundamentals of decision making and priority theory with the analytic hierarchy process. vol. VI of AHP Series. Pittsburgh: RWS Publications. 478 p.

San-Jose, J. T.; Cuadrado, J. 2010. Industrial building design stage based on a system approach to their environmental sustainability, Construction and Building Materials 24(4): 438-447. http://dx.doi.org/10.1016/j.conbuildmat.2009.10.019

San-Jose, J. T.; Garrucho, I. 2010. A system approach to the environmental analysis of industrial buildings, Building and Environment 45(3): 673-683.

http://dx.doi.org/10.1016/j.buildenv.2009.08.012
Williams, T. M. 1992. Practical use of distributions in network analysis, Journal of the Operational Research Society 43(3): 265-270. http://dx.doi.org/10.1057/jors.1992.35

Zadeh, L. A. 1975a. The concept of a linguistic variable and its application to approximate reasoning (I), Information Sciences 8(3): 199-249. http://dx.doi.org/10.1016/0020-0255(75)90036-5

Zadeh, L. A. 1975b. The concept of a linguistic variable and its application to approximate reasoning (II), Information Sciences 8(4): 301-357. http://dx.doi.org/10.1016/0020-0255(75)90046-8

Zadeh, L. A. 1975c. The concept of a linguistic variable and its application to approximate reasoning (III), Information Sciences 9(1): 43-80. http://dx.doi.org/10.1016/0020-0255(75)90017-1

Zadeh, L. A.; Fu, K.; Tanaka, K.; Shimura, M. 1975. Fuzzy sets and their applications to cognitive and decision processes. Oxford: Academic Press Inc. 496 p.

\section{Appendix 1}

\section{Alpha-cut-based arithmetic operations}

Fuzzy sets, fuzzy numbers and alpha-cuts have been defined previously. This example considers the case of two triangular fuzzy numbers $X=[a, b, c]$ and $Y=[A, B, C]$ whose membership functions are:

$$
\begin{gathered}
\mu_{X}(x)=\left\{\begin{array}{l}
\frac{(x-a)}{(b-a)}, a \leq x \leq b ; \\
\frac{(c-x)}{(c-b)}, b \leq x \leq c ;
\end{array}\right. \\
\mu_{Y}(x)=\left\{\begin{array}{l}
\frac{(x-A)}{(B-A)}, A \leq x \leq B ; \\
\frac{(C-x)}{(C-B)}, B \leq x \leq C .
\end{array}\right.
\end{gathered}
$$

The $X$ and $Y$ alpha-cuts are:

$$
\begin{gathered}
{ }^{\alpha} X=[(b-a) \times \alpha+a, c-(c-b) \times \alpha] ; \\
{ }^{\alpha} Y=[(B-A) \times \alpha+A, C-(C-B) \times \alpha] .
\end{gathered}
$$

Interval arithmetic can be applied in order to calculate the addition of $X$ and $Y$, by adding up the $X$ and $Y$ alpha-cuts:

$$
{ }^{\alpha} X+{ }^{\alpha} Y=[a+A+(b-a+B-A) \times \alpha, c+C-(c-b+C-B) \times \alpha] .
$$

Making both components of ${ }^{\alpha} X+{ }^{\alpha} Y$ equal $x$ :

$$
\begin{aligned}
& x=a+A+(b-a+B-A) \times \alpha ; \\
& x=c+C-(c-b+C-B) \times \alpha .
\end{aligned}
$$

Subsequently, expressing $\alpha$ in terms of $x$ and setting $\alpha=0$ and $\alpha=1$ in ${ }^{\alpha} X+{ }^{\alpha} Y$, we obtain $\alpha$ and the domain of $x$ :

$$
\begin{gathered}
\alpha=[x-(a+A)] /[(b+B)-(a+A)],(a+A) \leq x \leq(b+B) ; \\
\alpha=[(c+C)-x] /[(c+C)-(b+B)],(b+B) \leq x \leq(c+C) .
\end{gathered}
$$

Resulting in the membership function $\mu_{X+Y}(x)$ :

$$
\mu_{X+Y}(x)=\left\{\begin{array}{l}
\frac{x-(a+A)}{(b+B)-(a+A)},(a+A) \leq x \leq(b+B) ; \\
\frac{(c+C)-x}{(c+C)-(b+B)},(b+B) \leq x \leq(c+C) .
\end{array}\right.
$$

So if $X=[a, b, c]$ and $Y=[A, B, C]$, then $X+Y=[a+A, b+B, c+C]$, obtaining the same result as that obtained by applying the Zadeh Extension Principle. The reader can find additional information on fuzzy arithmetic and alpha-cut methods in Dong et al. (1985), Kaufmann and Gupta (1985), and Ross (2010). 
Alfredo del CAÑO. BSc MSc PE PhD Mechanical/Industrial Engineering, Technical University of Madrid (Spain). Professor of Construction Engineering and Management at the University of A Coruña (Spain). He has been Assistant and Associate Professor at the Technical University of Madrid, and Associate Professor at UNED (National University for Distance Education). Experience as project engineer, project manager, consultant, and operations manager working for private sector engineering and consultancy companies. Experience as software engineer working for the IT Center of the School of Industrial Engineering of the Technical University of Madrid. Topics of interest: project management, risk, uncertainty, procurement; design and construction of industrial complexes; sustainability assessment and management.

M. Pilar de la CRUZ. BSc MSc PE PhD Industrial Engineering, Technical University of Madrid. Associate Professor of Construction Engineering and Management, University of A Coruñ. She has been Assistant Professor of Business Administration at the Universities of A Coruña and Valladolid (Spain). Topics of interest: project management, risk, uncertainty, procurement; design and construction of industrial complexes; sustainability assessment and management.

Diego GÓMEZ. BSc MSc PhD Mechanical/Industrial Engineering, University of A Coruña. He has been research assistant, Research Associate and Research Fellow at the University of A Coruña. Dr Gómez has taught project management and industrial architecture at the Universities of A Coruña and Santiago de Compostela (Spain). He has been member of the Materials Working Group of Breeam ES, for the adaptation of BRE Environmental Assessment Method (BREEAM) to Spain. He is currently Project Engineer at Intacta Gestión Ambiental, an engineering and contracting company working in the environmental field. Topics of interest: project management, uncertainty; construction; environmental engineering; sustainability.

Miguel PÉREZ. BSc MSc Mechanical/Industrial Engineering. He has been research assistant at the University of A Coruña. He has worked at the Department of Urban Planning and Engineering of the Ferrol Municipality and the Department of Occupational Risk Prevention at Grupo Tragsa (Spain). He is currently working for Tecnocom at the Deployment and After Sales Department of R Cable y Telecomunicaciones Galicia (Spain). Topics of interest: safety management; uncertainty; construction; sustainability. 